\title{
Trilha interpretativa como proposta de Educação Ambiental: um estudo na RPPN do Caju (SE)
}

\author{
Interpretative trail as a proposal for Environmental \\ Education: a study in the RPPN of the Caju (SE, Brazil)
}

\author{
Isabelle Aparecida Dellela Blengini, Luana Brito Lima, \\ Isadora Souza de Mélo Silva, Cae Rodrigues
}

\begin{abstract}
RESUMO: A problemática ambiental é um tema que progressivamente, vem ganhando espaço nas discussões estabelecidas pela sociedade civil em diferentes âmbitos, por estar relacionada de maneira direta com o modelo econômico vigente e com a oposição ser humano-natureza. Por isso, se faz necessária a busca por alternativas que valorizem a natureza e fortaleçam a conexão, ou religare (em latim), entre as partes. Uma possibilidade, nesse sentido, é o contato com a natureza por meio das trilhas interpretativas, nas quais os aspectos de uma determinada área natural são evidenciados, transformando a interação de uma caminhada em um momento de ensino e aprendizagem marcado pela reflexão e o empoderamento da importância dessas localidades. A pesquisa teve como objetivo a proposição de adequações na Trilha da Porteira, localizada dentro da Reserva Particular do Patrimônio Natural (RPPN) do Caju, em Itaporanga d'Ajuda - SE, dando opções e qualidade ao processo de aprendizagem no âmbito da Educação Ambiental. A pesquisa foi realizada durante os meses de julho e agosto de 2018 e é fruto das atividades do Programa de Mestrado em Desenvolvimento e Meio Ambiente da Universidade Federal de Sergipe, no qual as autoras realizaram uma experiência de ação interdisciplinar tendo como resultado a proposta de uma trilha interpretativa em uma RPPN do estado de Sergipe. A metodologia seguiu três momentos: o primeiro foi a revisão bibliográfica; o segundo foi a visita de campo com a construção do diagnóstico relacionado à qualidade estrutural e didática da trilha; e o terceiro, a definição dos pontos de atratividade da trilha. A área de estudo foi a trilha do Campo Experimental da Embrapa Tabuleiros Costeiros, mais conhecido como Reserva do Caju. Como resultado obteve-se a proposta da Trilha Interpretativa da Porteira, que será apresentada para a Embrapa como mais uma opção de atividade educacional a ser realizada na localidade, valorizando ainda mais a RPPN do Caju.
\end{abstract}

PALAVRAS-CHAVE: Ecoturismo; Reservas Particulares do Patrimônio Natural; Conservação Ambiental. 


\section{ABSTRACT}

The environment is posed as a contemporary and greatly important issue, being directly related to the current economic model and to the human-nature opposition, legitimating the search for alternatives that value nature and strengthen the connection, or religare (in Latin), between the parts. One possibility in this sense is the contact with nature through interpretive trails, in which the aspects of a given natural area are evidenced, transforming the interaction of a walk into a moment of teaching and learning marked by reflections and dynamics of empowerment related to the importance of these localities. The research aimed the proposition of adjustments in the Porteira trail, located inside the Reserva Particular do Patrimônio Natural do Caju ('Cashew' Private Natural Heritage Reserve), in Itaporanga d'Ajuda (Sergipe, Brazil), giving options and adding quality to learning processes in environmental education in the site. The research was carried out during July and August of 2018, and is the result of activities connected to the PostGraduate Program in Development and Environment of the Federal University of Sergipe, in which the authors performed an interdisciplinary action-experience, resulting in the proposal of an interpretative trail in a Private Natural Heritage Reserve in the state of Sergipe. The methodology was divided in three steps: bibliographic review; field visit and construction of the diagnosis related to the structural and didactic quality of the trail; and defining the points of attractiveness of the Trail. The study area was the Embrapa Tabuleiros Costeiros Experimental Field Trail, better known as Caju Reserve. As a result, the proposal for the creation of the Porteira Interpretive Trail was drafted, which will be presented to Embrapa as another option to be carried out in the locality, valuing it even more as a potential site for the research and practice of Environmental Education.

KEYWORDS: Ecotourism; Private Natural Heritage Reserve; Environmental Conservation.

\section{Introdução}

É perceptível que na atualidade tem se buscado cada vez com maior intensidade, alternativas que venham conectar o ser humano com o meio natural, tendo como uma possibilidade o desenvolvimento de atividades em áreas naturais como trilhas interpretativas. Sendo assim, essa pesquisa tem como objetivo propor adequações na Trilha da Porteira, localizada dentro da Reserva Particular do Patrimônio Natural (RPPN) do Caju, em Itaporanga d'Ajuda-SE, pois tais adequações podem vir a contribuir para trazer um estímulo mais aprofundado com a natureza para evidenciar a importância da área e de atividades planejadas, com propósitos estabelecidos pela Educação Ambiental.

No estado de Sergipe, segundo dados do Sistema Informatizado de Monitoria de RPPN - SIMRPPN, existem oito RPPNs, dentre elas a do Caju. Nosso objeto de estudo, localizado no município de Itaporanga d'Ajuda é propriedade da Empresa Brasileira de Pesquisa Agropecuária (Embrapa). Compreende-se que uma RPPN é um campo de possiblidades e estratégias que viabilizam a conservação dos ecossistemas e que, ao integrar a 
sociedade civil com o poder público, possibilita a concretização da práxis da Educação Ambiental e uma oportunidade para o ecoturismo.

O caminho metodológico percorrido para a realização desse trabalho foi iniciado com a revisão documental das legislações e a revisão bibliográfica, por ter como propósito possibilitar a definição da RPPN escolhida no Estado de Sergipe. Posteriormente, foi realizada a coleta de dados em campo para a construção de um diagnóstico dessa RPPN. Para a realização dessa coleta de dados foi utilizada uma planilha de observação, que foi preenchida no campo pelas pesquisadoras e sistematizadas em tabelas. Essa sistematização produziu um diagnóstico que ajudou na construção de proposta da trilha interpretativa.

\section{Referencial teórico}

\section{Educação Ambiental no contexto das RPPNs}

Após praticamente cinquenta anos de construção teórica além de debates e ações no campo da política, a Educação Ambiental (EA) passou a gozar de certa legitimidade como caminho possível para a mudança de paradigma necessária na busca de resolução das questões ambientais. No Brasil, a Constituição Federal de 1988 reconheceu o direito de todos os cidadãos brasileiros à EA e atribui ao Estado o dever de promover a EA em todos os níveis de ensino, e de conscientizar a sociedade a respeito da importância da preservação do meio ambiente. Em 1999, inclusive, foi aprovada a lei no 9.795 que dispõe sobre a Política Nacional de Educação Ambiental (PNEA), a qual promulga que todas as escolas brasileiras devem inserir a EA nos seus currículos. Nela, a EA é caracterizada no Art. $1^{\circ}$ como:

\footnotetext{
Os processos por meio dos quais o indivíduo e a coletividade constroem valores sociais, conhecimentos, habilidades, atitudes e competências voltadas para a conservação do meio ambiente, bem de uso comum do povo, essencial à sadia qualidade de vida e sua sustentabilidade.
}

Deste modo, a preocupação com o meio ambiente deve ter como alvo a mudança de posturas e comportamentos no modo de viver. Para que essa preocupação seja consciente é necessária a realização de uma EA crítica, emancipatória e transformadora, com finalidades de proporcionar uma alfabetização ecológica (UNGARÓ et al., 2007).

De acordo com Carvalho (2004), a passagem da EA para um novo paradigma parece ser um dos caminhos de transformação que desponta da convergência entre mudança social e ambiental. Ao ressignificar o cuidado à natureza e ao outro (humanos-e-não-humanos) a partir de atitudes baseadas em valores ambientalmente ético-políticos (RODRIGUES, 2018; 2015), a EA crítica se afirma em uma posição balizadora de decisões sociais e reorientadora de estilos de vida coletivos e individuais (LOPES, 2006). Com 
essa nova consciência educacional, delineiam-se novas racionalidades, constituindo os laços identitários de uma cultura política ambiental, com o objetivo de promover mudanças de caráter social, político e humano.

De acordo com o Tratado de Educação Ambiental para Sociedades Sustentáveis e Responsabilidade Global (BRASIL, 1992):

A Educação Ambiental deve promover a cooperação e o diálogo entre indivíduo e instituição, com a finalidade de criar novos modos de vidas, baseados em atender as necessidades básicas de todos, sem distinções étnicas, físicas, de gênero, idade, religião, classes ou mentais.

Ao se pensar então na realização de processos de EA, no âmbito não formal, é necessário realizar um estudo prévio da localidade, compreender os aspectos socioambientais, culturais, econômicos e os conflitos para se ter um diagnóstico prévio, pois quando é aplicada a realização de processos de $E A$ nessa pesquisa se obtém clareza de que a EA que se busca não é uma simples atividade pontual em uma área natural, mas sim a realização de algo mais profundo, capaz de dar sentido a uma prática mais complexa, que perpassa justamente por novas metodologias, novos sentimentos e novas ações. Tais propostas agregam valor, por exemplo, a RPPN, categoria de Unidade de Conservação da Natureza (UC) empregadas no Brasil como um mecanismo que possibilita a proteção ambiental a partir da criação de espaços com objetivos específicos voltados para a conservação da biodiversidade. Uma UC é assim definida:

\footnotetext{
Art. $2^{\circ}$ Para os fins previstos nesta Lei, entende-se por:

I - Unidade de conservação: espaço territorial e seus recursos ambientais, incluindo as águas jurisdicionais, com características naturais relevantes, legalmente instituído pelo Poder Público, com objetivos de conservação e limites definidos, sob regime especial de administração, ao qual se aplicam garantias adequadas de proteção; (BRASIL, 2000).
}

Reconhecendo-se a relevância da definição legal acima é importante também reconhecer que o histórico normativo que gere as RPPNs, segundo Wiedmann (1997; 2001), é anterior à legislação específica das UCs. A ideia de conservação e proteção de terras privadas já era prevista desde o antigo Código Florestal de 1934, uma que vez se inseriam no escopo das chamadas florestas protetoras. Podemos também fazer uma associação com a Constituição brasileira de 1988, em seu artigo 225, quando estabelece a todos o "direito ao meio ambiente ecologicamente equilibrado, bem de uso comum do povo e essencial à sadia qualidade de vida" (BRASIL, 1988), pois a ideia de proteção e conservação das terras privadas possibilita uma garantia de efetividade do direito ao meio ambiente ecologicamente equilibrado. 
Por meio do Decreto no 1.922, de 5 de junho de 1996, o termo Reserva Particular do Patrimônio Natural foi formalmente conceituado:

\begin{abstract}
Art.1ำ Reserva Particular do Patrimônio Natural - RPPN é área de domínio privado a ser especialmente protegida, por iniciativa de seu proprietário, mediante reconhecimento do Poder Público, por ser considerada de relevante importância pela sua biodiversidade, ou pelo seu aspecto paisagístico, ou ainda por suas características ambientais que justifiquem ações de recuperação.
\end{abstract}

Embora o conceito de propriedade particular destinada à conservação ambiental já existisse expressamente desde o Código Florestal de 1934, segundo o MMA (2006), foi essa definição de RPPN de 1996 que possibilitou o início do reconhecimento governamental perante o desejo de proprietários rurais de protegerem suas terras. Apesar desse avanço, as RPPNs ainda não eram reconhecidas como UCs. Apenas com o Sistema Nacional de Unidades de Conservação da Natureza (SNUC), instituído pela Lei 9.985/2000, se estabeleceu critérios e normas para a criação, implementação e gestão das UCs federais, sendo as RPPNs incorporadas como categoria de UC de uso sustentável.

Segundo o art. 7으, § 2으, da Lei 9.985/2000, as UCs de uso Sustentável têm como objetivo "compatibilizar a conservação da natureza com o uso sustentável de parcela dos seus recursos naturais", definindo o "uso sustentável" em seu art. 2ำ, XI, como a "exploração do ambiente de maneira a garantir a perenidade dos recursos renováveis e dos processos ecológicos, de forma socialmente justa e economicamente viável'. Nessa lei, a RPPN é assim definida:

Art. 21. A Reserva Particular do Patrimônio Natural é uma área privada, gravada com perpetuidade, com o objetivo de conservar a diversidade biológica.

(...)

$\S 2$ o Só poderá ser permitida, na Reserva Particular do Patrimônio Natural, conforme se dispuser em regulamento:

I - a pesquisa científica;

II - a visitação com objetivos turísticos, recreativos e educacionais;

II - (VETADO).

Além da Lei 9.985/2000, o decreto nํ 5.746, de 5 de abril de 2006, que regulamentou o art. 21 da lei do SNUC, traz a seguinte definição: 


\begin{abstract}
Art. 1ㅇ A Reserva Particular do Patrimônio Natural - RPPN é unidade de conservação de domínio privado, com o objetivo de conservar a diversidade biológica, gravada com perpetuidade, por intermédio de Termo de Compromisso averbado à margem da inscrição no Registro Público de Imóveis.
\end{abstract}

Parágrafo único. As RPPNs somente serão criadas em áreas de posse e domínio privados.

As RPPN possuem grande relevância para a conservação da biodiversidade, por sua iniciativa de criação voluntária do proprietário do território, ganhando destaque assim, como a única categoria de posse e domínio exclusivamente particular (MESQUITA, 2004; PINTO, 2004; OLIVEIRA, 2010). A iniciativa de criação espontânea pelo proprietário é exclusiva da RPPN. Esta é a única categoria de unidade de conservação que pode ser criada a partir da iniciativa do próprio dono da terra, segundo regulamentado pelo decreto $\mathrm{n}^{\circ} 5.746 / 06$ :

\begin{abstract}
Art. 3 O proprietário interessado em ter seu imóvel, integral ou parcialmente, transformado em RPPN, deverá, no âmbito federal, encaminhar requerimento ao IBAMA, solicitando a criação da RPPN, na totalidade ou em parte do seu imóvel, segundo o modelo do Anexo I deste Decreto, e na forma seguinte:

I - o requerimento relativo a propriedade de pessoa física deverá conter a assinatura do proprietário, e do cônjuge ou convivente, se houver;

II - o requerimento relativo a propriedade de pessoa jurídica deverá ser assinado pelos seus membros ou representantes com poder de disposição de imóveis, conforme seu ato constitutivo e alterações posteriores; e

III - quando se tratar de condomínio, todos os condôminos deverão assinar o requerimento ou indicar um representante legal, mediante a apresentação de procuração.
\end{abstract}

Essas áreas possuem uma vocação especial para o desenvolvimento de atividades que podem se tornar ecopedagógicas, tendo em vista que atividades de cunhos científico, cultural, educacional, recreativo e de lazer (art. 3ํㅡㄹ BRASIL, 1996) podem ser realizadas nos espaços de RPPN. Segundo o ICMBio (2012), as RPPN são importantes também porque contribuem para a ampliação das áreas protegidas no país; apresentam índices altamente positivos para a conservação; são facilmente criadas, em relação às outras categorias de UC; possibilitam a participação da iniciativa privada no esforço nacional de conservação; e contribuem para a proteção da biodiversidade dos biomas brasileiros. 


\title{
Ecoturismo e trilhas interpretativas
}

Associado ao proceso de maior legitimação do movimento ambiental nos anos 1970, de acordo com MELO (2018): "o ecoturismo surgió como movimiento ambiental global como respuesta a las preocupaciones por el desarrollo económico, la degradación ambiental y cuestiones sociales provocadas por la masificación del turismo", resultando na possiblidade de realização de uma atividade turística na natureza que atendesse às chamadas de mínimo impacto e de responsabilidade ambiental. No Brasil, diante do fortalecimento das discussões relativas à questão ambiental nos anos 1990, foi decretado, em 1994, o documento "Diretrizes para uma Política Nacional de Ecoturismo", lançado em conjunto, pelo Ministério da Ciência e Tecnologia e pelo Ministério do Meio Ambiente, em parceria com o Instituto Brasileiro de Turismo (EMBRATUR) e o Instituto Brasileiro do Meio Ambiente e dos Recursos Naturais Renováveis (IBAMA). A partir daí, o ecoturismo é evidenciado como "alternativa" turística, considerando-se as possibilidades do desenvolvimento deste segmento em áreas naturais com elevados índices de biodiversidade e pressões antrópicas de degradação ambiental (BRASIL, 2010). Nessa perspectiva, as Diretrizes para uma Política Nacional de Ecoturismo (2010, p.15) conceituam ecoturismo como:

\begin{abstract}
É um segmento da atividade turísticas que utiliza, de forma sustentável, o patrimônio natural e cultural, incentiva a conservação e busca a formação de uma consciência ambientalista através da interpretação do ambiente, promovendo o bem-estar das populações envolvidas.
\end{abstract}

Outro conceito importante de ecoturismo é instituído pela Sociedade Internacional de Ecoturismo (TIES), que define ecoturismo como uma viagem responsável a áreas naturais, visando a conservação do meio ambiente e a promoção do bem-estar da população local ${ }^{1}$ (HAWKINS, 2001).

Sendo assim, ao olhar para a definição de ecoturismo de acordo com as diretrizes citadas, nota-se que o ecoturismo traz a vertente da conscientização/sensibilização, o que deve ocorrer por meio da EA, incluindo na perspectiva da interpretação ambiental, o que possibilita um direcionamento a atividades como as trilhas interpretativas. Nesse sentido, quando é pensado em ecoturismo na perspectiva da $E A$, as atividades em trilhas são uma ferramenta bastante integrada ao conceito, sendo elas ecológicas, interpretativas, com enfoque na reflexão e discussão relacionada às questões ambientas da localidade, com objetivos de turismo ou lazer, o que permite o conhecimento sobre a fauna, a flora, as relações ecológicas e socioambientais da área, e visam uma maior conexão com a natureza.

Mas o que são trilhas interpretativas? Não são somente um caminho na mata; são a possibilidade de realizar uma atividade na qual são traduzidas diversas informações e explicadas com linguagem mais atrativa e simplificada, dependendo do público. Por isso, devem ser planejadas para agregar conhecimento sobre a localidade visitada, e consequentemente 
garantirem a tradução da linguagem da natureza, no sentido que se torna mais compreensível para diferentes grupos, principalmente visitantes que moram em grandes centros urbanos e que buscam uma maior interação com a natureza (GUILLAUMON, 1977; DIAS, 1986; FONTES, 2003); transformando a simples recreação em oportunidade prazerosa de aprendizado (VASCONCELLOS, 2004).

Assim, as trilhas ecológicas interpretativas se enquadram em percursos interpretativos orientados metodologicamente, não devendo ser confundidas com apenas "picadas abertas na mata", sempre sendo associadas a processos com potencial educativo. As trilhas interpretativas, como uma forma de EA, devem visar não somente a transmissão de conhecimentos específicos, mas também propiciar atividades que revelam os significados e as características do ambiente por meio do uso dos elementos originais, experiência direta e meios ilustrativos, podendo ser usadas como instrumento básico em programas de educação ao ar livre (PÁDUA; TABANEZ, 1997).

Neste processo, a Educação Ambiental pode ocorrer a partir da combinação de práticas pedagógicas formais e informais, e desta maneira, possibilitar o aumento de conhecimento e a mudança de valores, bem como o fortalecimento da relação ser humano-natureza, contribuindo para a conscientização dos indivíduos sobre a importância da conservação e qualidade do ambiente (BLENGINI, 2012). É nessa perspectiva que se potencializa a integração do ecoturismo e da EA a partir da implantação de trilhas interpretativas.

\section{Metodologia}

Em um primeiro momento, para a realização desse estudo foi necessário fazer uma revisão documental, visando entender a legislação que regulamenta a categoria de UC - a RPPN - sua importância e suas problemáticas no cenário nacional e estadual. Para a contextualização do problema também foi realizada uma pesquisa bibliográfica, buscando referências científicas para basear a proposta de intervenção. Diante da identificação da necessidade de pesquisas acerca das RPPNs, especialmente no estado de Sergipe, foi necessário escolher uma das RPPNs locais para a realização do estudo, considerando as limitações temporais para a realização da pesquisa.

Em um segundo momento, foi realizada a coleta de dados em campo para a construção de um diagnóstico. Para essa etapa foi utilizada uma planilha de observação, a qual foi preenchida no campo pelas pesquisadoras e sistematizadas em tabelas. Essa coleta foi realizada na área da Reserva no dia 27 de julho de 2018, durante uma visita de campo. A planilha de observação foi construída visando compreender o que existia na área, especialmente em relação ao que poderia ser implementado na realização de processos de EA. Como se trata de uma RPPN com legislação própria, tal legislação foi a base para a construção da planilha. 
Nessa planilha, as pesquisadoras computaram a presença ou ausência dos atributos naturais e os pontos de atratividade da trilha, a partir de suas próprias observações e análise interpretativa. Essa observação foi centrada no ambiente e foi sistematizada pelas pesquisadoras em tabelas para serem sistematizadas na forma de um diagnóstico relacionado à qualidade estrutural, e também em relação a abordagem didática feita pelo guia da trilha para que, em um terceiro momento, fossem escolhidos os pontos de atratividade da trilha interpretativa.

\section{Caracterização da área de estudo}

O Campo Experimental da Embrapa Tabuleiros Costeiros, mais conhecido como Reserva do Caju, fica localizada no município de Itaporanga d'Ajuda-SE, aproximadamente a 1,5 Km da balsa da Caueira, $20 \mathrm{~km}$ de Aracaju e $41 \mathrm{Km}$ da sede do Município de Itaporanga d'Ajuda. É uma RPPN e foi adquirida pela Embrapa em 1979, possuindo 910 hectares, dos quais 760 estão em processo de implantação (Figura 1). O local apresenta os ecossistemas Mata Atlântica, Restinga e Manguezal, além de campos de aprendizagem (vitrines) com os experimentos que a Embrapa realiza (EMBRAPA, 2009).

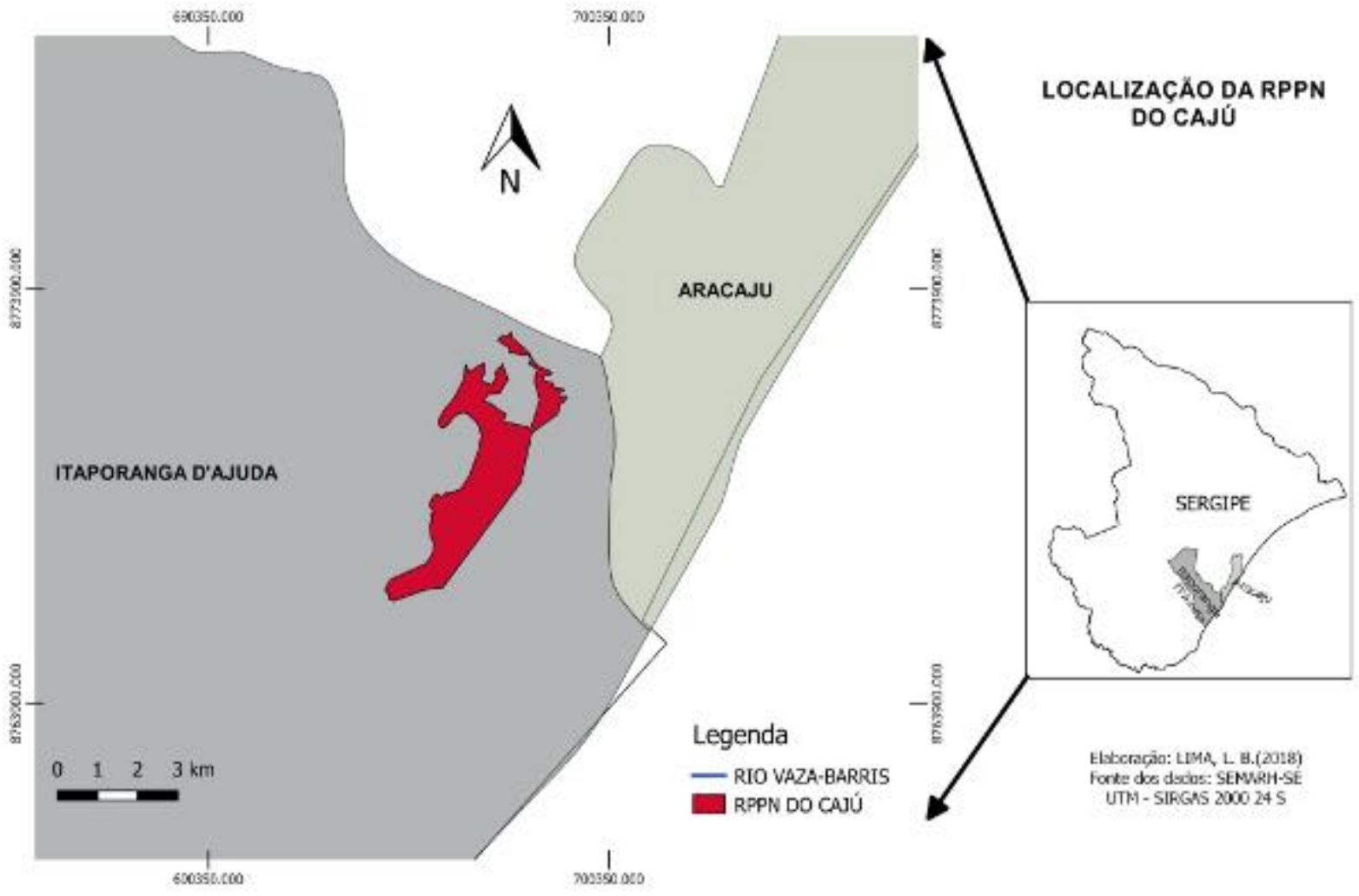

Figura 1: Mapa de localização da RPPN do Caju.

Figure 1: Location map of the Caju RPPN.

Fonte: elaboração dos próprios autores (2018).

Source: prepared by the authors (2018). 
A RPPN do Caju recebeu esse nome por causa dos cajueiros presentes na propriedade, que a tonaram conhecida regionalmente como Fazenda do Caju. Antes de se tornar uma RPPN, a Fazenda do Caju era um Campo Experimental de Itaporanga (CEI); o objetivo da localidade é fomentar a pesquisa científica e difundir técnica sobre a cultura do coqueiro (EMBRAPA, 2015). Posteriormente, parte desse CEI foi transformado na RPPN do Caju, cujo registro no Diário Oficial da União (DOU) se deu pela Portaria $\mathrm{n}^{\circ} 4$, de 17 de janeiro de 2011 (BRASIL, 2011). A EA é um dos objetivos regulares da RPPN do Caju. Atividades envolvendo estudantes e pesquisadores voltados para a conservação da natureza costumam ocorrer nas duas trilhas da RPPN: a Trilha da "Ilha do Boi" e a Trilha da Porteira (EMBRAPA, 2015), esta última, objeto de adequação da intervenção proposta nesse estudo.

O critério de escolha foi a localização da RPPN, já que é a mais próxima de Aracaju, capital do estado de Sergipe, cidade que se destaca pelo seu grande potencial turístico, contando com atrações turísticas como o Mercado Municipal, a Orla de Atalaia, a Orla Pôr do Sol, os bancos de areia do Rio Vaza-Barris, parques urbanos, etc. Segundo dados oficiais, em 2017, desembarcaram 603.789 pessoas no Aeroporto Internacional Santa Maria em Aracaju; no ano de 2016, a cidade contava com 221 estabelecimentos hoteleiros, com 68,54\% de ocupação (SERGIPE, 2018).

Além disso, a escolha pela RPPN do Caju se justifica devido às atividades educativas já realizadas na localidade. A RPPN recebe uma grande quantidade de alunos de escola públicas e particulares, tem a presença de 3 biomas (Mata Atlântica, Restinga e Manguezal) e é gerenciada por uma empresa pública, a Embrapa, que desenvolve alguns projetos de pesquisa e desenvolvimento tecnológico dentro dela.

\section{Coleta de dados de campo}

A visita à RPPN do Caju teve autorização da Embrapa. Durante a visita foi possível constatar que a gestão da reserva possui um programa de EA voltado aos alunos de ensino fundamental e médio que visitam a RPPN, onde conhecem os experimentos que a Embrapa realiza na localidade, e fazem uma caminhada de cerca de $1 \mathrm{~h}$ e $30 \mathrm{~min}$, na Trilha da Porteira. A trilha passa por 2 biomas, Mata Atlântica e Restinga, onde é possível encontrar diversas espécies da fauna e flora típicas desses ambientes. No roteiro, ainda é possível visitar um sítio arqueológico tombado pelo Instituto do Patrimônio Histórico e Artístico Nacional (IPHAN). A caminhada pela trilha pelas pesquisadoras foi o principal procedimento metodológico para verificar as potencialidades dessa trilha em relação à $E A$, e permitiu propor adequações.

Durante a caminhada pela trilha foi realizado um diagnóstico relacionado à qualidade estrutural e didática da mesma e das informações passadas pelo guia e coordenador da RPPN; a partir desse diagnóstico foi possível propor algumas ações que visam tornar a trilha "comum" em uma trilha com viés interpretativo. A trilha interpretativa tem grande respaldo na 
bibliografia científica como instrumento efetivo para a EA. As trilhas interpretativas são consideradas alternativas para trabalhos educativos em campo a partir da análise de seus recursos ambientais e da interpretação dos recursos ambientais. Nestas trilhas, a paisagem é compreendida como recurso didático e, através da interpretação ambiental, os visitantes podem ser informados e sensibilizados sobre a complexidade ambiental (OLIVEIRA et al, 1999).

Enquanto a trilha foi percorrida pelas pesquisadoras, foram realizadas anotações em diários de campo sobre as condições de segurança, o estado de conservação, a facilidade de circulação e a sinalização. Com auxílio de um receptor Global Navigation Satellite System (GNSS) e da planilha de observação, foram marcados os possíveis pontos de atratividade da trilha. Após seleção das características relevantes, foi possível estabelecer 6 pontos de paradas onde devem ser conduzidas as etapas de interpretação. Foi considerada, também, a necessidade de implantação de placas informativas aos visitantes.

\section{Resultados e Discussão}

A partir do diagnóstico realizado se constatou que a RPPN, de maneira geral, possui uma estrutura adequada para receber os turistas; tem um centro de administração que possui estrutura sala e cozinha, além de um auditório onde são realizadas palestras com estudantes que visitam a reserva. Além disso, os equipamentos de infraestrutura estão em boas condições para a prática do ecoturismo.

Como resultado dessa pesquisa uma proposta de Trilhas Interpretativas da Porteira foi definida. Com 6 pontos, ela poderá ser implementada durante as visitas já realizadas na RPPN do Caju; tais pontos foram definidos a partir da coleta de dados em campo com o diagnóstico relacionado à qualidade estrutural e didática da trilha. A Figura 2 mostra 0 mapa com a localização dos 6 pontos de atratividades encontrados na trilha. O diagnóstico apontou que a trilha da porteira tem grande potencial para a implementação de uma trilha interpretativa, devido aos seguintes atributos: a) sua biodiversidade conservada com grande riqueza de fauna e flora; b) suas características de resgate histórico das antigas populações que habitaram a localidade; c) sua boa estrutura para realizar caminhadas de forma leve e tranquila; d) a procura por esse tipo de atividade pelos mais diversos públicos; e) a necessidade de um nivelamento de informação que possam estar disponíveis aos visitantes. 


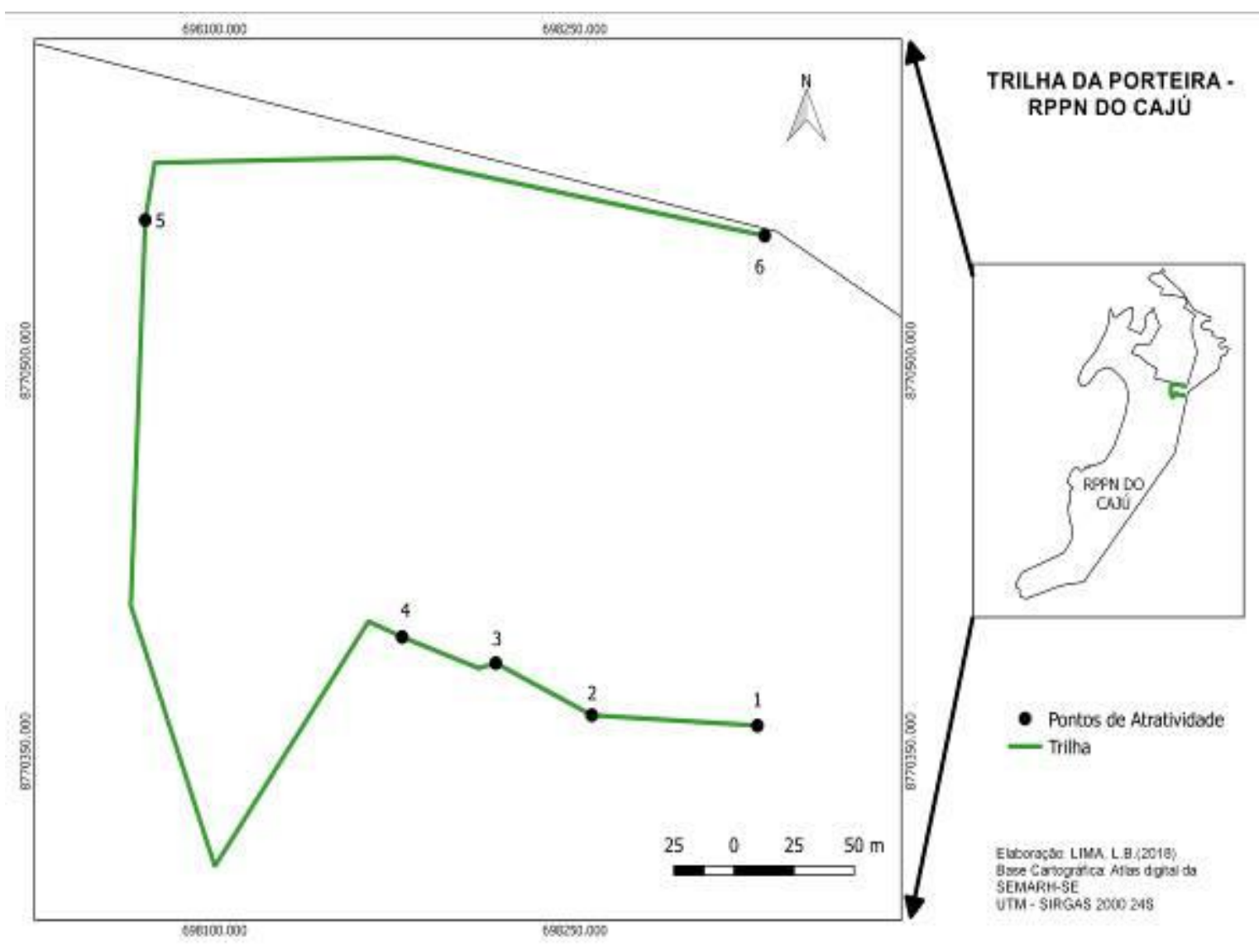

Figura 2: Mapa de localização dos pontos de atratividade

Figure 2: Location map of attractiveness points. Fonte: elaboração dos próprios autores (2018).

Source: prepared by the authors (2018).

A trilha interpretativa pensada buscou, a partir desses atributos, estabelecer pontos de atratividade para futuras visitações com foco em EA. Algumas das informações para a proposta foram encontradas no Plano de Manejo da RPPN e detalhadas durante a pesquisa. Esses pontos podem ser explorados didaticamente, em especial, no ensino formal; porém, caso seja implantada com placas informativas, a trilha poderá ser visitada por qualquer pessoa, sem a necessidade de um guia.

\section{Pontos de parada para explanar sobre o tema ou placas}

Em geral, as trilhas interpretativas são classificadas com duas possibilidades de realização: 1 - as trilhas guiadas, aquelas com a presença de um guia com o devido treinamento que, durante o percurso, irá conduzir o visitante e trazer informações, levando-os a observar, sentir, experimentar, questionar e descobrir os fatos relacionados ao tema estabelecido; e 2 - as trilhas autoguiadas, que são aquelas nas quais o visitante faz o percurso com pontos de parada marcados por placas, painéis ou por folhetos contendo informações em cada ponto, e o percurso é explorado sem o 
acompanhamento de um guia (VASCONCELLOS, 1998). Porém, essas possiblidades podem também se complementarem, como a realização de trilhas guiadas onde existem placas, por exemplo; nesse caso, o guia pode, além de trabalhar com os temas das placas, trazer novos elementos que, muitas vezes, são únicos daquele determinado momento, como uma pegada, uma floração de alguma espécie, entre inúmeras outras possiblidades.

Nesse trabalho, todas as possibilidades foram exploradas, podendo a trilha ser realizada de forma autoguiada com o auxílio de placas fixas que deverão conter as informações levantadas, ou pode ser realizada com um guia que desenvolverá as temáticas de discussão predefinidas, sendo ainda possível a integração entre os dois métodos. Os pontos elencados serão pontos de paradas durante o percurso da trilha. No caso da trilha guiada, o condutor será responsável por passar as informações; caso sejam colocadas placas, as informações ficarão disponíveis de forma permanente e os visitantes poderão realizar visitas autoguiadas.

\section{Pontos de atratividade definidos}

A seguir se apresenta a descrição dos 6 pontos que são considerados mais interessantes para a implementação da Trilha Interpretativa da Porteira. Os pontos definidos foram: 1) Entrada da trilha; 2) Embaúba; 3) Cupinzeiro; 4) Sítio Arqueológico; 5) Mangaba; 6) Finalização. A duração da trilha interpretativa deverá ser, aproximadamente de 1 h e $30 \mathrm{~min}$, com percurso de 819 metros. A trilha é dividida em dois momentos: o primeiro dentro da mata fechada e o segundo na mata aberta.

Caso sejam implantadas as placas na trilha, será necessário que o material seja resistente, sendo indicada a criação de totens de madeira (que causam menos impacto), visando a menor interferência na localidade, considerando para a escolha do material a ser utilizado as relações entre a durabilidade, o custo e a estética (TRAPP, 1994). Tais placas têm como objetivo chamar a atenção para um tema específico relacionado à localidade onde estas se encontram, cumprindo deste modo, a função de discutir a importância da conservação das áreas naturais; e evidenciando também aspectos ambientais, sociais e históricos da localidade.

\section{Ponto 1: Entrada da Trilha}

O primeiro ponto da trilha é justamente sua entrada, que tem como objetivo dar informações básicas sobre a conduta na área e as normas de segurança durante o percurso, assim como a respeito da duração da caminhada e a extensão do percurso. No caso da Trilha da Porteira já existe uma placa com essas informações em sua entrada (Figura 3). Esse momento deve ser trabalhado com o intuito de despertar a curiosidade dos visitantes. 


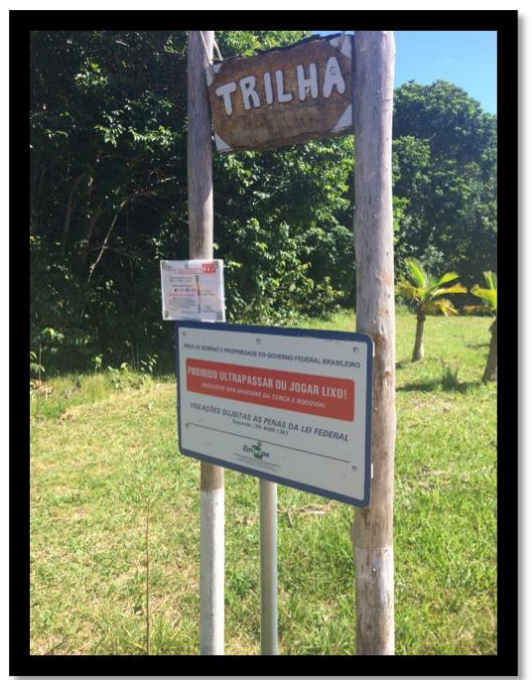

Figura 3: Entrada da Trilha ponto 1. Fonte: Próprios autores (2018). Figure 3: Track entry point 1. Source: By the authors (2018).

\section{Ponto 2: Embaúba}

O segundo ponto tem como objetivo trazer explicações sobre a Embaúba (Cecropia pachystachya), Família: Cecropiaceae. Pontos de discussão podem incluir: abordagem sobre sucessão ecológica e sua função na natureza; explicação sobre sua função como árvore pioneira, sendo encontrada em áreas degradadas ou nas bordas das matas; algumas características de espécie também podem ser salientadas, como seu médio porte (pioneira, 4 a 8 metros de altura), madeira fraca, crescimento rápido, folhas compostas com 8 partes de $40 \mathrm{~cm}$, flor e sementes aparecem como um pequeno cacho no topo da árvore - fonte de alimento para o bicho preguiça ( $B$. torquatus) e outros animais que se alimentam das folhas mais novas - além de oferecer alimento para uma diversidade de pássaros, assim como morada para vários tipos de insetos, como formigas e cupins. Sua época de floração ocorre em setembro e a frutificação, em junho.

\section{Ponto 3: Cupinzeiro}

Esse ponto se centra na abordagem sobre o Cupinzeiro e na explicação de que o cupim também vive em estruturas da sociedade. Os pontos de discussão podem incluir: 1- explicação sobre a organização social dos cupins; por exemplo, como todos os cupins são eussociais e possuem castas estéreis (soldados e operários); 2 - como uma colônia típica é constituída de um casal reprodutor - rainha e rei - ocupado apenas na tarefa de reprodução, e de produção de ovos; 3 - a organização com inúmeros operários, que realizam o trabalho e alimentam a colônia cuidando das outras castas e soldados que são responsáveis pela defesa da sociedade. Outra questão importante a ser explorada é a função dos cupins na natureza, já que eles têm um papel importante como decompositores, na reciclagem de matéria orgânica e na aeração do solo quando constroem galerias; além disso, cabe explicar que os cupins vivem em ninhos que podem ser construídos sob ou sobre troncos, no solo e também em construções (Figura 4) . 


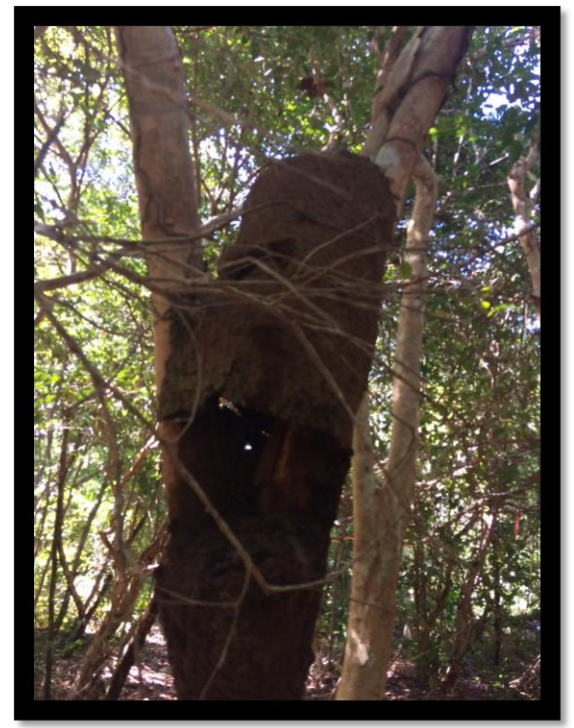

Figura 4: Ponto 3. Fonte: Próprias autoras (2018).

Figure 4: Point 3. Source: By the authors (2018).

\section{Ponto 4: Sítio Arqueológico}

O objetivo do sítio arqueológico é ressaltar a importância dessa área, onde foram encontrados vestígios de antiga ocupação humana, e comentar sobre os utensílios domésticos encontrados na localidade que estão expostos no Museu da Gente Sergipana (Figura 5). O principal ponto de discussão é sobre a importância dessa área como sítio arqueológico reconhecido pelo Instituto do Patrimônio Histórico e Artístico Nacional IPHAN. São registrados como sítios arqueológicos apenas aqueles que apresentam importância científica para compreensão da história da humanidade. São estes sítios arqueológicos (com raras exceções) que são estudados pelos arqueólogos. Já existem mais de 4 mil sítios arqueológicos registrados em território brasileiro, sendo 155 em Sergipe, de acordo com o IPHAN (2019).

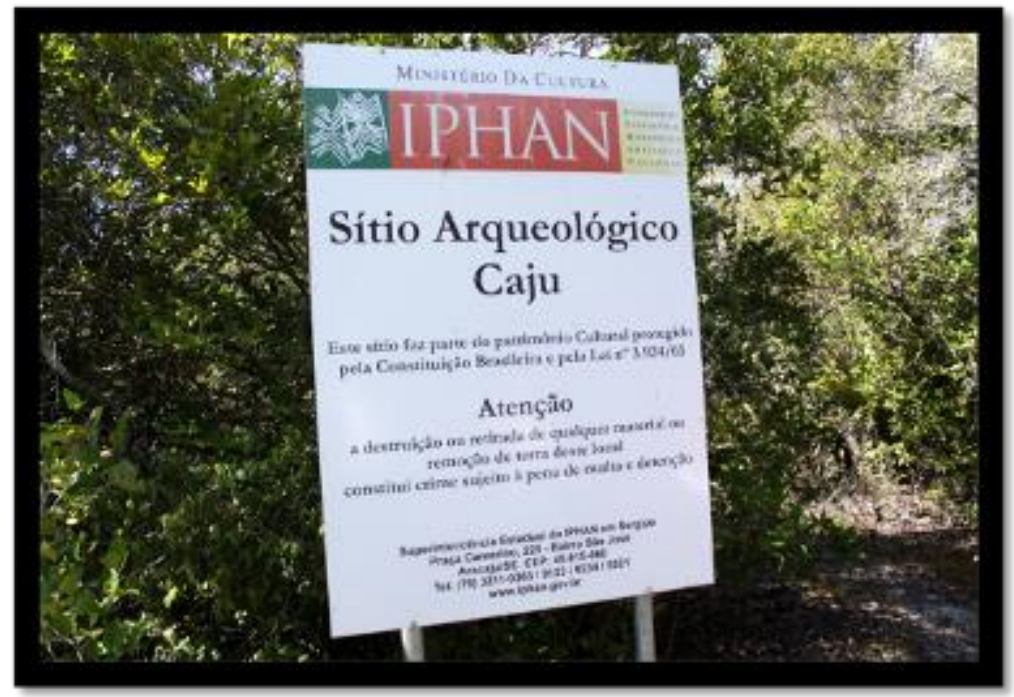

Figura 5: Ponto 4. Fonte: Próprias autoras (2018). Figure 5: Point 4. Source: By the authors (2018). 


\section{Ponto 5: Mangaba}

Esse ponto tem como objetivo ressaltar a importância da mangaba, fruto da mangabeira (Hancornia speciosa). Os pontos de discussão podem incluir: questões sobre a produção e comercialização da mangaba - Sergipe é o maior produtor do Nordeste; questões de gênero envolvidas no processo de produção da mangaba - as mulheres englobam quase toda a coleta do fruto; assim como a transformação do fruto em outros produtos, envolvendo processos artesanais e manejo sustentável. Não podem ser esquecidas outras questões associadas a processos contemporâneos de produção a partir do exemplo da mangaba - espécie nativa da região, porém relativamente pouco conhecida in natura pelos Sergipanos, sendo mais consumida na forma de sorvete e polpa concentrada. E, por fim, deve ser feita a apresentação da Mangabeira como árvore símbolo de Sergipe, instruído pelo Decreto no 12.723 de 20 de janeiro de 1992, tendo, desta forma, um papel muito importante com o seu uso sustentável, o que é realizado principalmente pelas cooperativas de catadoras de mangaba.

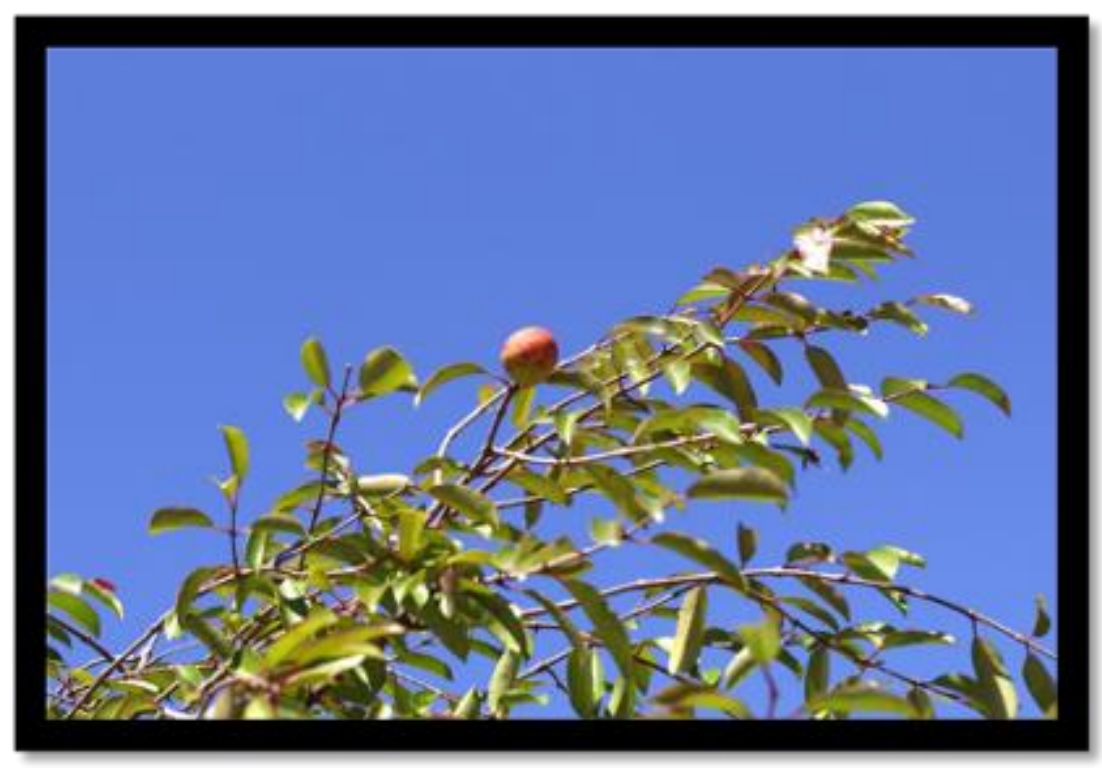

Figura 6: Ponto 6. Fonte: Próprias autoras (2018).

Figure 6: Point 6. Source: By the authors (2018)

\section{Ponto 6: Finalização}

Esse ponto pretende realizar um levantamento sobre a percepção dos participantes em relação ao percurso da trilha. No caso de uma trilha guiada, o próprio guia pode realizar uma dinâmica com esse intuito; ou no caso de uma trilha autoguiada, a coleta de questionário com esse objetivo. Para a finalização da trilha sugere-se também uma avaliação do processo, para que futuras lacunas sejam identificadas e sanadas. 


\section{Considerações Finais}

A pesquisa com RPPN no estado de Sergipe é relativamente pequena em comparação a estados como Paraná e São Paulo, os quais são dotados de legislação estadual e municipal específica para essa categoria de UC. Desse modo, dar visibilidade a essas áreas no estado de Sergipe tem grande importância, visto a necessidade de avançar em políticas públicas de conservação no estado.

A pesquisa realizada trouxe a possiblidade de compreender as limitações e as possibilidades para realização da EA em RPPN, podendo transcender ações pontuais, e trazer novos olhares para as áreas naturais com grande potencial educativo. Outro ponto importante a ser considerado é a realização da EA como processo, sendo essa uma tarefa difícil frente à dificuldade de dar continuidade aos projetos no ensino formal e não formal, já que, muitas vezes, os projetos são realizados por pessoas previamente definidas. Dessa forma, ao se pensar na realização do projeto de EA é importante que seja um processo continuado e assumido pela instituição.

$\mathrm{Na}$ proposta, Trilha Interpretativa da Porteira é o nome dado ao resultado de um processo de pesquisa que buscou conectar características da área da trilha com o detalhamento de informações que possam ser interpretadas pelos visitantes, de modo que um passeio em uma área natural possa trazer, de forma lúdica, o conhecimento das características dessa área, valorizando e difundindo valores da conservação ambiental. Desta maneira, a Trilha Interpretativa da Porteira pode ser um caminho para 0 processo de EA, pois traz elementos de ação-reflexão sobre novas formas de se trabalhar as questões ambientais fora dos muros das escolas e com os mais diversos públicos

A proposta da trilha interpretativa demostra ser uma possiblidade para trabalhar temas que muitas vezes não são conhecidos por pessoas que não tiveram a oportunidade de vivenciar uma experiência em uma área natural, principalmente em contextos atuais, nos quais a vida cotidiana se passa, majoritariamente, em áreas urbanas. Nesse sentido, o visitante da trilha interpretativa tem a possiblidade de conhecer, por exemplo, a mangabeira, espécie tão importante para o sergipano, dado que no estado, ela é reconhecida como árvore símbolo, instruído pelo Decreto nํㅜ 12.723 de 20 de janeiro de 1992, tendo um papel muito importante em seu uso sustentável. Ao longo da trilha, o visitante pode, inclusive, conhecer a árvore de perto, ver o fruto e saber da sua história.

Perante o que foi exposto, a adequação da Trilha da Porteira, para que se torne também uma trilha interpretativa, é uma proposta viável, visto que esse potencial foi confirmado pela pesquisa realizada. Os pontos de atratividades já foram marcados e detalhados com informações aprofundadas. O próximo passo será a apresentação da proposta aos representantes do Campo Experimental da Embrapa Tabuleiros Costeiros, onde fica localizada a trilha, sendo sugerida a implantação da trilha, assim como a formação de guias e a construção de placas, caso possível. 


\section{Referências}

BRASIL. Lei no 9795, de 27 de abril de 1999: Institui a Política Nacional de Educação Ambiental e dá outras providências. Diário Oficial da União, Brasília, 28 abr. 1999.

BRASIL. Tratado de Educação Ambiental para as Sociedades Sustentáveis e Responsabilidade Global. Política Nacional de EA - Lei no 9.795/99. Regulamento de PNEA - decreto 4.281/02 - 92.

BRASIL. Decreto no 5.746, de 5 de abril de 2006. Regulamenta o art. 21 da Lei no 9.985 , de 18 de julho de 2000, que dispõe sobre o Sistema Nacional de Unidades de Conservação da Natureza. Brasília, 2011. Disponível em: $<$ http://www.planalto.gov.br/ccivil 03/ Ato2004 > . Acessado em 20/10/2017.

BRASIL. Lei no 9.985, de 18 de julho de 2000. Institui o Sistema Nacional de Unidades de Conservação da Natureza e dá outras providências. Presidência da República Federativa do Brasil. Disponível em:<http://www.presidencia.gov.br/legislacao >. Acessado em 20/10/2017.

BLENGINI, I. A. D. et al. Trilhas interpretativas em Educação Ambiental: estratégia de conservação e uso sustentável da biodiversidade Universidade Federal da Bahia. FÓRUM BRASILEIRO DE EDUCAÇÃO AMBIENTAL, 7, Salvador. Anais...Salvador: 2012.

CARVALHO, I. C. M. Educação Ambiental Crítica: nomes e endereçamentos da educação. In: LAYRARGUES, P. P. (Org.). Identidades da Educação Ambiental Brasileira. Brasília: Ministério do Meio Ambiente, 2004. p.13-24.

DIAS, A.C.; NETTO, B.V.D.M.; MARCONDES, M.A.P. Trilha Interpretativa do Rio Taquaral - Parque Estadual de Carlos Botelho. Bol. Técn. do Inst. Flor., São Paulo, 40-A: 11-32

FONTES, M.A.L.; VITORINO, M.R.; SALVATI, S.S. 2007. Urbanização. In: Ecoturismo e interpretação, Lavras: UFLA /FAEPE, 2003.

GUILLAUMON, J.R.; POLL, E.; SINGY, J.M. 1977. Análise das Trilhas de Interpretação. Boletim Técnico do Instituto Florestal, São Paulo, 25.

HAWKINS, D. E.; KARIN, M. M.; Oportunidades para o turismo ecológico nos países em desenvolvimento. In THEOBALD, W. (Org) Turismo global. São Paulo: Ed Senac São Paulo, 2001

INSTITUTO NACIONAL DO PATRIMÔNIO HISTÓRICO E ARTÍSTICO NACIONAL. Patrimônio Arqueológico. Disponível em: < $<$ http://portal.iphan.gov.br/pagina/detalhes/1430/>. Acesso em: 20/01/2019

LOPES, J. S. L. Sobre processos de "ambientalização" dos conflitos e sobre dilemas da participação. Horizontes Antropológicos, ano 12, n.25, p.31-64, 2006.

MELO, M. R. S. Contribución del ecoturismo a la conservación del guacamayo rojo (arara-vermelha) en una reserva de Brasil, Estudios y perspectivas en turismo v.27, n.1 Ciudad Autónoma de Buenos Aires ene. 2018 
OLIVEIRA, R. T.; BLOOMFIELD, V. K.; MAGALHÃES, L. M. S. Trilha auto guiada: proposta de implantação e interpretação na Floresta Nacional Mário Xavier Sandra Regina da Costa. Floresta e Ambiente, v.6, n.1, p.138-143, 1999.

PADUA, S. M. Cerrado Casa Nossa: um projeto de Educação Ambiental do jardim botânico de Brasília. Brasília: UNICEF, 1997. 35pp.

GOVERNO DO ESTADO DE SERGIPE. Observatório de Sergipe. Sergipe em Números: síntese 2018. Disponível em: < $<$ http://observatorio.se.gov.br/estatistica/sergipe-em-numeros/>. Acesso em $12 / 01 / 2018$.

RODRIGUES, C. Movement Scapes as ecomotricity in ecopedagogy. The Journal of Environmental Education, v.49, n.2, p.88-102, 2018.

RODRIGUES, C. O vagabonding como estratégia pedagógica para a "desconstrução fenomenológica" em programas experiencias de Educação Ambiental. Educação em Revista, v.31, n.01, p.303-327, 2015.

SIQUEIRA, L. F. Trilhas interpretativas: uma vertente responsável do (eco) turismo. Caderno Virtual de turismo, no14, 2004.

UNGARO, P.; SOUZA, J. G.; LEAL, A. C. Educação Ambiental e educação infantil: a criança e a percepção do espaço. Revista Brasileira de Educação Ambiental, n.2, p.53-62, 2007.

VASCONCELLOS, J. M. O. Trilhas interpretativas: aliando educação e recreação. In: Congresso Brasileiro de Unidades de Conservação, 1, 1997, Curitiba. Anais... Curitiba: IAP, UNILIVRE, REDE PRÓ-UC, 1997, v.1, p.465477.

VASCONCELLOS, J. M. O. (1998). Avaliação da visitação pública e da eficiência de diferentes tipos de Trilhas Interpretativas do Parque Estadual Pico do Marumbi e Reserva Natural Salto Morato - PR. Tese de Doutorado do Curso de Pós-graduação em Engenharia Florestal, UFPR.

VASCONCELLOS, J.M.O. Avaliação da eficiência de diferentes tipos de trilhas interpretativas no Parque Estadual Pico do Marumbi e Reserva Natural Salto Morato - PR. Revista Brasileira de Conservação da Natureza, Curitiba, 2: 48-57.

TABANEZ, M. F.; PADUA, S. M. (ORGS.) 1997. Educação Ambiental: caminhos trilhados no Brasil. Instituto de Pesquisas Ecológicas - IPÊ. Brasília.

WIEDMANN, S. M. P. As reservas particulares do patrimônio natural. In: CONGRESSO BRASILEIRO DE UNIDADES DE CONSERVAÇÃO, 2, Curitiba. Anais... p.3-14, v. II. Trabalhos Técnicos. Curitiba, 1997.

WIEDMANN, S. M. P. Reserva Particular do Patrimônio Natural - RPPN - na Lei no. 9.985/2000 que institui o Sistema Nacional de Unidades de Conservação - SNUC. In: BENJAMIN, A. H. (Ed.). Direito ambiental das áreas protegidas. Rio de Janeiro: Editora Forense Universitária, 2001. 


\section{Nota}

1 Nossa tradução para: Ecotourism is: "Responsible travel to natural areas that conserves the environment and improves the well-being of local people". The International Ecotourism Society, 1990. Disponível em http://www.ecotourism.org. Acesso em: 05/08/18

\section{Agradecimentos}

O presente trabalho foi realizado com apoio da Coordenação de Aperfeiçoamento de Pessoal de Nível Superior - Brasil (CAPES) - Código de Financiamento 001

Isabelle Aparecida Dellela Blengini: Universidade Federal de Sergipe, Aracaju, SE, Brasil.

E-mail: belle_biologia@yahoo.com.br

Link para o currículo Lattes: http://lattes.cnpq.br/4964279126673857

Luana Brito Lima: Universidade Federal de Sergipe, Aracaju, SE, Brasil.

E-mail: luaanabritoo@gmail.com

Link para o currículo Lattes: http://lattes.cnpq.br/7430240271483621

Isadora Souza de Mélo Silva: Universidade Federal de Sergipe, Aracaju, SE, Brasil.

E-mail: isadorasouzademelo@hotmail.com

Link para o currículo Lattes: http://lattes.cnpq.br/5589949250980441

Cae Rodrigues: Universidade Federal de Sergipe, Aracaju, SE, Brasil.

E-mail: rodrigues.cae@gmail.com

Link para o currículo Lattes: http://lattes.cnpq.br/6159440346233422

Data de submissão: 30 de outubro de 2018

Data de recebimento de correções: 27 de novembro de 2018

Data do aceite: 27 de novembro de 2018

Avaliado anonimamente 